\title{
THE EFFECT OF BORON AND ZIRCONIUM ON MICROSTRUCTURE AND STRESS-RUPTURE LIFE OF NICKEL-BASED SUPERALLOY ATI 718PLUS
}

\author{
Seyed Ali Hosseini*, Seyed Mehdi Abbasi, Karim Zanganeh Madar \\ Metallic Materials Research Center, Malek Ashtar University of Technology (MUT), \\ Tehran, Iran
}

Received 10.10.2015

Accepted 03.11.2015

\begin{abstract}
The effects of boron and zirconium on the microstructure, hardness and stressrupture life of the nickel-based superalloy ATI 718Plus were investigated in this study. Four alloys with different percentages of boron (0.005-0.01 wt.\%) and zirconium (0-0.1 $\mathrm{wt} \%)$ were cast through a vacuum induction melting furnace and then were rolled. The microstructural studies indicated an increased percentage of $\delta$ phase, carbide precipitates and twins in the presence of zirconium. The percentage of carbide (boron carbide) precipitates was increased and the solidification range of the alloy was decreased in the presence of boron in the composition. Furthermore, the results obtained from the hardness and stress-rupture tests showed the significant role of both elements in increasing hardness and improved rupture life of the alloy. The maximum rupture life was observed in the alloy which contained the highest percentages of boron and zirconium in its composition. This can be attributed mainly to the increased percentage of $\delta$ phase on grain boundaries and their enhanced high-temperature strength.

Keywords: boron, zirconium, 718Plus alloy, microstructure, Stress-rupture life.
\end{abstract}

\section{Introduction}

The nickel-based superalloy 718Plus was first introduced by ATI Allvac in the early 1990s [1]. The thermal stability of this alloy is greater than that of IN718 alloy up to $55{ }^{\circ} \mathrm{C}$. It also has higher weldability, hot workability and production ease as compared to other alloys such as Waspaloy and Rene $41[2,3]$. One of the main reasons of the thermal stability of 718Plus compared to IN718 is the greater percentage of phase $\gamma^{\prime}$ and the smaller percentage of phase $\gamma^{\prime \prime}$ in its microstructure [4, 5]. The high percentage of $\gamma^{\prime}$ phase in 718Plus is obtained by increasing the sum of $\mathrm{Al}+\mathrm{Ti}$, the ratio of $\mathrm{Al} / \mathrm{Ti}$ and reducing the amount of iron by adding cobalt and tungsten, respectively $[6]$.

* Corresponding author: Seyed Ali Hosseini, salihomarim@gmail.com 
For the first time in 1950, material science researchers found out that the presence of small amounts of boron and zirconium in composition of nickel-based superalloys significantly improves their mechanical properties [7, 8]. Since then, the addition of these elements to superalloys to improve mechanical properties, particularly those sensitive to grain boundary effects has increased dramatically.

Decker and Freeman [7] examined the effect of $0.009 \mathrm{wt} \%$ boron and $0.01 \mathrm{wt} \%$ zirconium on the mechanical properties of a nickel-based alloy known as $55 \mathrm{Ni}-20 \mathrm{Cr}$ 15Co-4Mo. The results suggested an improvement in creep properties, ductility and hot workability of the alloy as well as a reduction in structural micro-cracks. Antony and Radavich [9] also reported the positive effect of boron and the negative effect of zirconium in reducing the micro-porosities and improving the stress-rupture life of a nickel-based superalloy. In addition, Zhu et al. [10] showed the decreased level of micro-segregations in the solidification structure of IN718 in the presence of $0.009 \mathrm{wt} \%$ boron. They stated that this amount of boron leads to an increased volume percentage and size for Laves phase and the degradation of mechanical properties of the alloy. Additional studies [11-16] were conducted to evaluate the effect of boron and zirconium on microstructure and mechanical properties of IN718, which demonstrated its importance.

Thus, the propose of this study was to examine the effect of boron and zirconium on the microstructure, hardness and stress-rupture life of 718Plus, which has never been investigated so far, aiming at further enhancing of its thermal stability.

\section{Experimental work}

Nickel-based superalloy 718Plus with different percentages of boron and zirconium, was cast in a $30 \times 60 \times 70-\mathrm{mm}, 1-\mathrm{kg}$ vacuum induction melting (VIM) furnace. The chemical composition of the alloy was determined through Optical Emission Spectrometer for major elements and Inductively Coupled Plasma for boron and zirconium, according to Table 1 .

Table 1. Chemical composition of 718Plus alloy in the presence of boron and zirconium $(w t \%)$.

\begin{tabular}{|c|c|c|c|c|c|c|c|c|c|c|c|c|}
\hline Alloy & Ni & $\mathbf{C r}$ & $\mathbf{F e}$ & $\mathbf{C o}$ & $\mathbf{N b}$ & $\mathbf{M o}$ & $\mathbf{A l}$ & $\mathbf{T i}$ & $\mathbf{W}$ & $\mathbf{C}$ & $\mathbf{Z r}$ & $\mathbf{B}$ \\
\hline Base & Bal & 18.98 & 9.21 & 9.85 & 5.48 & 2.78 & 1.47 & 0.72 & 0.89 & 0.012 & 0.00 & 0.005 \\
\hline Zr-doped & Bal & 18.63 & 9.17 & 9.78 & 5.40 & 2.73 & 1.42 & 0.74 & 0.85 & 0.011 & 0.10 & 0.005 \\
\hline B-doped & Bal & 18.91 & 9.09 & 9.69 & 5.42 & 2.75 & 1.44 & 0.75 & 0.86 & 0.013 & 0.00 & 0.011 \\
\hline $\begin{array}{c}\text { Zr/B- } \\
\text { doped }\end{array}$ & Bal & 18.65 & 9.13 & 9.71 & 5.41 & 2.77 & 1.43 & 0.73 & 0.83 & 0.011 & 0.10 & 0.010 \\
\hline
\end{tabular}

In order to determine the phase transformation temperature in the microstructure of the base alloy, the differential thermal analysis (DTA) was carried out in the temperature range of $750-1300^{\circ} \mathrm{C}$ with a heating rate of $10{ }^{\circ} \mathrm{C} / \mathrm{min}$ under argon atmosphere. The homogenization heat treatment was done on the samples at $1125^{\circ} \mathrm{C}$ for 5 hours, so as to reduce internal stresses and undesirable Laves phase [17]. After the rolling process of alloys, solution heat treatment at $968{ }^{\circ} \mathrm{C}$ for 1 hour, the aging was performed on the samples through two stages: the first of which was aged at $788^{\circ} \mathrm{C}$ for 
8 hours and cooled at $38^{\circ} \mathrm{C}$ per hour in the furnace, whereas the second stage was aging at $704{ }^{\circ} \mathrm{C}$ for 8 hours followed by air cooling.

The metallographic samples were prepared by two solutions Kalling's No. 2 reagent and Ferric Chloride to analyze the microstructure and macrostructure, respectively. At the next stage, the microstructure of the alloys was examined through optical microscopy and scanning electron microscopy (SEM) equipped with energy dispersive spectroscopy (EDS). The hardness testing was done in accordance with ASTM E18 for samples aged at two conditions, whereas the stress- rupture life testing was performed according to AMS specifications, i. e. at $704^{\circ} \mathrm{C}$ under stress of $620 \mathrm{MPa}$.

\section{Results and Discussion}

Characterization of microstructure

Figure 1 shows the result of DTA analysis of the base alloy in as-cast condition. In Table 2, the DTA results are compared with those obtained by Cao [18] and Simona [19] regarding 718Plus alloy. For two $\gamma^{\prime \prime}$ and $\delta$ phases, which play an important role in the stability of 718Plus, there is a favorable consistency between the obtained results. Moreover, there is a good agreement between the dissolution temperature of $\gamma^{\prime}$ phase with Cao modeling [18] and the dissolution temperature of Laves and MC carbide phases with thermal analysis results obtained by Simona [19]. This implies the appropriate selection of conditions for casting and heat treatment of the alloys in the present study.

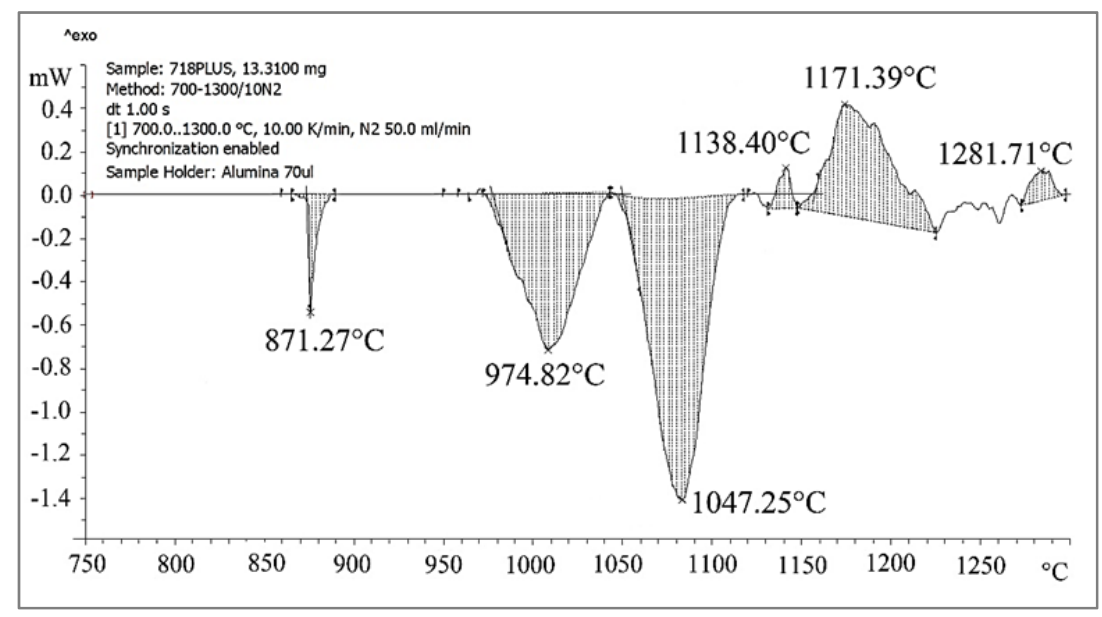

Fig. 1. DTA analysis results for casting alloy 718Plus (Graph is normalized).

The SEM images for the microstructure of the four alloys are illustrated in Figure 2. In Figure $2 \mathrm{a}$ the large cuboid precipitates of titanium nitride containing a slight amount of niobium were detected by EDS analysis on grain boundaries (Figure 3). According to Mitchell et al. [20], this phase, similarly observed in the microstructure of IN718 alloy, forms at temperatures above liquidus and prior to the alloy's freezing point, serves as a preferential spot for nucleation of carbide phases. This eventually leads to the formation of carbo nitride phases in the alloy's microstructure, the nucleus 
of which is made of titanium nitride [20]. Other precipitates in the base 718Plus include complex carbides of titanium, niobium and molybdenum ( $\mathrm{Ti}, \mathrm{Nb}, \mathrm{Mo}$ ) $\mathrm{C}$.

Table 2. Comparison of the phase transformation temperature of 718 Plus in this study and other studies (obtained by DTA analysis).

\begin{tabular}{|l|c|c|c|c|c|c|c|c|c|}
\hline \multicolumn{2}{|c|}{$\begin{array}{c}\text { Phase Transition } \\
\mathrm{T}\left({ }^{\circ} \mathrm{C}\right)\end{array}$} & $\begin{array}{c}\boldsymbol{\sigma} \\
\text { Solvus }\end{array}$ & $\begin{array}{c}\boldsymbol{\gamma}^{\prime \prime} \\
\text { Solvus }\end{array}$ & $\begin{array}{c}\boldsymbol{\gamma}^{\prime} \\
\text { Solvus }\end{array}$ & $\begin{array}{c}\boldsymbol{\delta} \\
\text { Solvus }\end{array}$ & $\begin{array}{c}\text { Laves } \\
\text { Eutectic }\end{array}$ & Solidus & $\begin{array}{c}\text { MC } \\
\text { Eutectic }\end{array}$ & Liquidus \\
\hline $\begin{array}{l}\text { Cao } \\
{[18]}\end{array}$ & Metallugraphy & - & $\begin{array}{c}954- \\
982\end{array}$ & $\begin{array}{c}1002- \\
1018\end{array}$ & - & - & - & - & - \\
\hline Modeling & 968 & 995 & 1065 & - & 1201 & 1261 & 1346 & - \\
\hline Simona (DTA) [19] & - & - & 990 & 1136 & 1179 & 1216 & 1283 & 1343 \\
\hline This research (DTA) & 871 & 975 & 1047 & 1138 & 1171 & - & 1282 & - \\
\hline
\end{tabular}
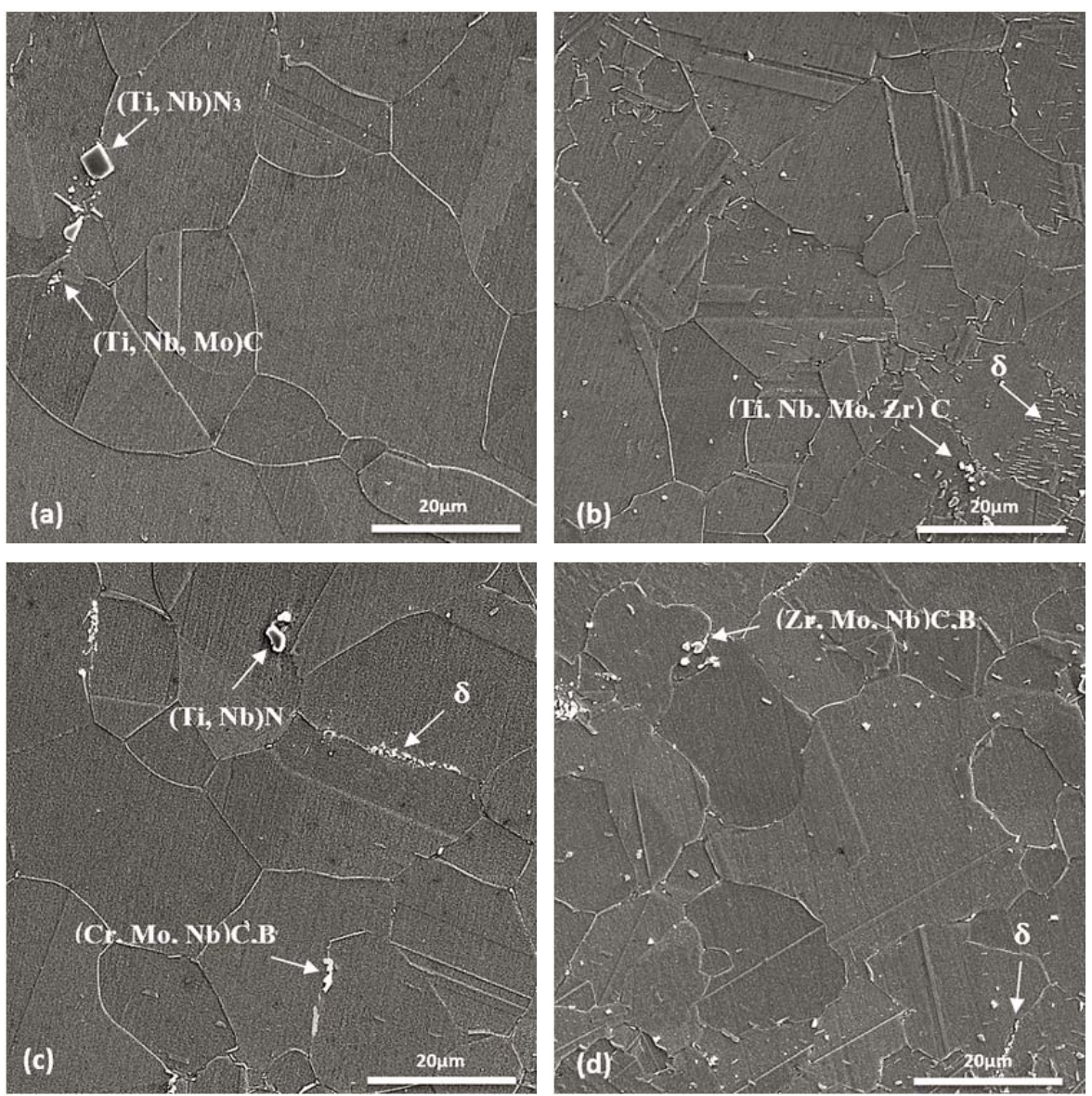

Fig. 2. The SEM images for the microstructure of the alloys a) base alloy, b) Zr-doped alloy, c) B-doped alloy, d) alloy containing both elements. 
Figure $2 \mathrm{~b}$ shows the microstructure of the Zr-doped alloy ( $0.1 \mathrm{wt} \%)$. In this alloy, the size of various precipitates such as titanium nitride has been significantly decreased. The effect of zirconium on increasing the percentage of carbide and $\delta$ phases, as well as their concentration on grain boundaries, is also significant. This is favorably consistent with the research done by Fedorova et al. [14], who examined the effect of boron and zirconium on IN718, pointing out the distinct impact of zirconium on increasing the percentage of $\delta$ phase and its agglomeration on grain boundaries, which resulted from the segregation of zirconium at $\delta$ phase.

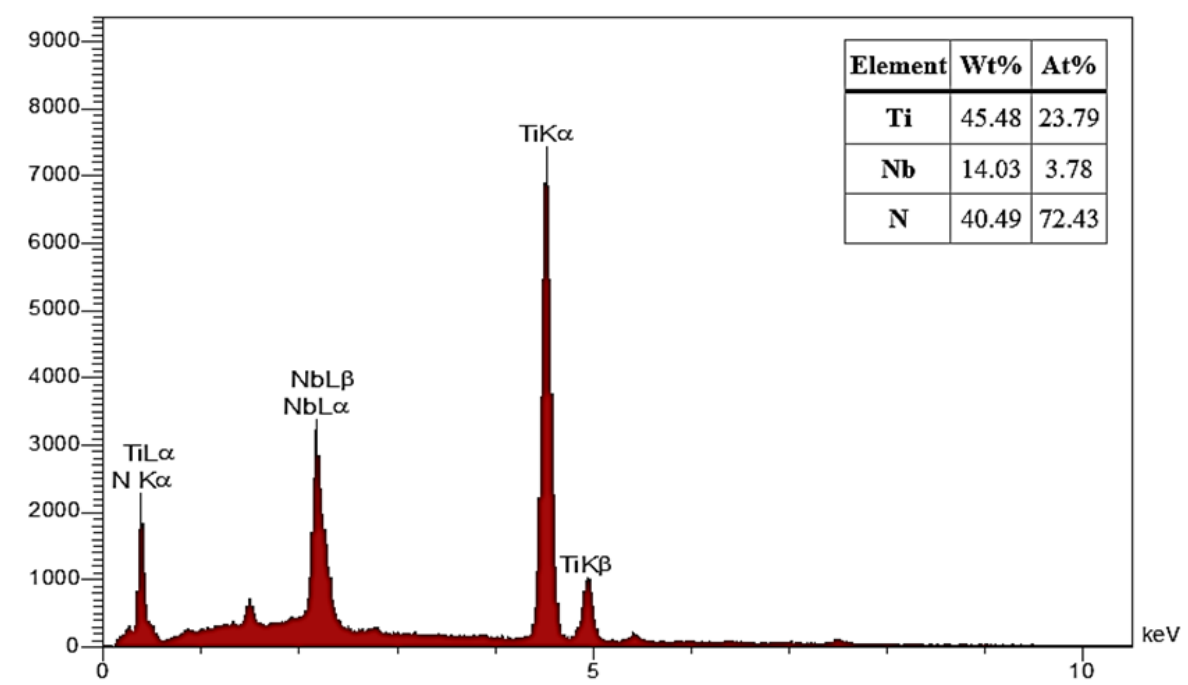

Fig. 3. The EDS analysis of the precipitates of titanium nitride (Ti, $\mathrm{Nb}$ ) $\mathrm{N}_{3}$ in base alloy 718 Plus.

According to Figure.$b$, zirconium also increases the twins in the microstructure of 718Plus. It can be attributed to the effect of zirconium on concentration of various precipitates along grain boundaries and changes in their morphology, which leads to decelerate the dislocations colliding with grain boundaries and raises their density. In this regard, Huang and Koo [21] reported that the presence of zirconium in CM 247 LC superalloy leads to reducing in size and morphological shift in carbide precipitates (spheroidizing) on grain boundaries. Such a change not only slows down the dislocation rate along the grain boundaries, but also delays the development of grain boundary cracks.

Figure 2c shows the microstructure of the B-doped alloy $(0.01 \mathrm{wt} \%)$. In the absence of zirconium in the alloy, smaller percentage of $\delta$ precipitates can be observed in the microstructure. However, boron similar to zirconium, decreases the size and increases the percentage of nitride and carbide precipitates in 718Plus, even though its effect on these phases is less than in the case of zirconium. In the presence of boron in the composition, the boron carbide phase $(\mathrm{Nb} \mathrm{Cr}, \mathrm{Mo}, \mathrm{B}, \mathrm{C}$ can also be observed on the grain boundaries. By improving the cohesion and strength of grain boundaries at high temperatures, these precipitates lead to increased stress-rupture life of the alloy. According to the research conducted by Federova et al. [14], the high percentage of boron $(0.02 \mathrm{wt} \%)$, accompanied with the formation of boron carbide precipitates on 
grain boundaries, leads to their embrittlement. As the grain boundaries become embrittled, hot cracks rapidly grow and the alloy's cast capability will be reduced.

Figure $2 \mathrm{~d}$ shows the microstructure of the alloy containing both boron and zirconium. The simultaneous presence of the two elements in the composition significantly increases the amount of various precipitates $(\delta$, carbide and boron carbide) and their concentration on grain boundaries. These precipitates are regarded as obstacles against mobility of dislocations and grain boundary sliding. As the grain boundaries are locked up by precipitates and slippage is prevented, their growth rate slows down. According to Table 3, the grain size in the alloy containing both boron and zirconium is significantly lower than that of the three last alloys.

Table 3. The grain size in the four alloys studied.

\begin{tabular}{|c|c|c|c|c|}
\hline Grain Size & Base-(718Plus) & Zr-doped & B-doped & Zr/B-doped \\
\hline Micron & $46 \pm 5$ & $37 \pm 5$ & $35 \pm 5$ & $28 \pm 5$ \\
\hline
\end{tabular}

In a study conducted on the interaction of boron and zirconium, Fedorova et al. [14] suggested that the presence of a high percentage of zirconium together with in IN718 composition can be an explanation for the intense agglomeration of phase $\delta$ on grain boundaries. In fact, the involvement of both elements in the composition increases the segregation of zirconium in phase $\delta$, which in turn, leads to the agglomeration of this phase. Decker et al. [7] similarly pointed out the significant effect of boron and zirconium on the agglomeration of $\gamma^{\prime}$ precipitates and $\mathrm{M}_{23} \mathrm{C}_{6}$ carbide on grain boundaries. As can be seen in Figure 4, the presence of the two elements together in the composition of 718Plus brought about intense agglomeration of boron carbide and $\delta$ phases on a few spots of the sample. The results of EDS analysis for $\delta$ precipitates are illustrated in Figure 5, indicate approximately $17.39 \mathrm{wt} \%$ zirconium in the composition of this phase at agglomerated areas.
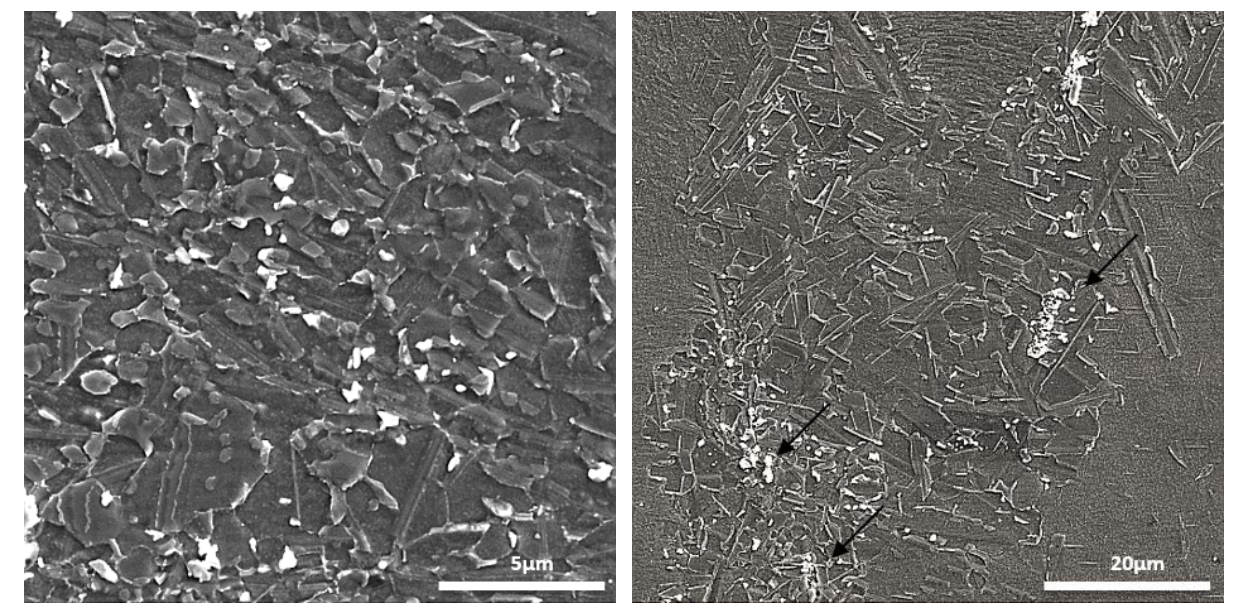

Fig. 4. Concentration of boron carbide and $\delta$ phases and their intense agglomeration in certain microstructure areas in the presence of both elements in 718Plus composition (magnified at two different scales). 


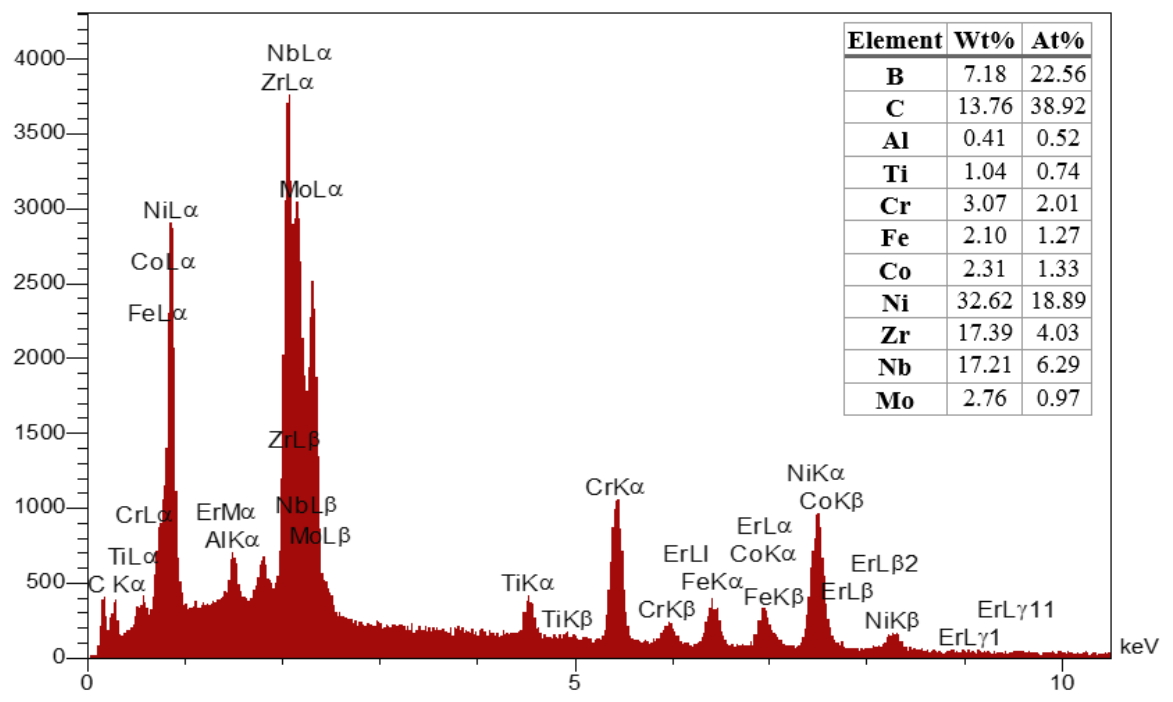

Fig. 5. The EDS analysis of agglomerated phase $\delta$ (involving high percentage of zirconium).

In order to determine the effective mechanism of boron and zirconium on the solidification condition of 718Plus, the solidification process of alloys was simulated through JmatPro. The results of this simulation were well consistent with those obtained by Simona et al. [19] in terms of solidification range and transformation temperature of $\gamma^{\prime}$ and $\delta$ phases (Table 4). The alloy's reduced solidification range in the presence of boron and its increase in the presence of zirconium, is among the additional results yielded by this simulation. Antony and Radavich [9], reported that zirconium in contrast of boron extended the solidification range and increased micro-porosities in the microstructure which tends to reduction of stress-rupture life in the presence of high percentage of zirconium.

Table 4. Simulation of the alloys solidification process and calculation of transformation temperatures through JmatPro.

\begin{tabular}{|c|c|c|c|c|c|c|}
\hline $\begin{array}{c}\text { Phase Transformation } \\
\mathrm{T}\left({ }^{\circ} \mathrm{C}\right)\end{array}$ & Liquidus & $\begin{array}{c}\text { MC } \\
\text { Eutectic }\end{array}$ & Solidus & $\mathbf{M}_{3} \mathbf{B}_{2}$ Solvus & $\begin{array}{c}\boldsymbol{\delta} \\
\text { Solvus }\end{array}$ & $\begin{array}{c}\boldsymbol{\gamma}^{\prime} \\
\text { Solvus }\end{array}$ \\
\hline Base (718Plus) & 1351 & 1269 & 1207 & 1180 & 1006 & 968 \\
\hline $\mathbf{Z r - d o p e d}$ & 1350 & 1266 & 1192 & 1174 & 1008 & 970 \\
\hline B-doped & 1351 & 1267 & 1210 & 1183 & 1006 & 969 \\
\hline $\mathbf{Z r}$ B-doped & 1348 & 1265 & 1197 & 1176 & 1008 & 970 \\
\hline
\end{tabular}

Mechanical properties

The hardness of alloys in solution treated and aged conditions are shown in Table 5. Both elements boron and zirconium raised the hardness of alloy. The main reason of this issue can be expressed in terms of the increase in percentage of various precipitates of $\delta$, carbide and boron carbide in the presence of these elements in 718Plus composition. As can be observed, the impact of zirconium has been rather remarkable 
on increased hardness. By being added to carbide composition and forming the precipitates of zirconium carbide, which is regarded as one of the hardest phases in nickel-based superalloys, zirconium significantly contributes to increase in the alloy's hardness level. On the other hand, a great tendency of zirconium to segregate on grain boundaries and concentrate carbide and $\delta$ precipitates raises the level of hardness and consequently, the embrittlement of the grain boundaries. The latter reduces the alloy's level of ductility. In this regard, Lin et al. [22] reported that the tendency of zirconium to segregate on grain boundaries is three times higher than the tendency to engage into the intra-granular space of a nickel-based alloy. Therefore, zirconium can effectively contribute to the alloy's ductility percentage over a critical limit through preventing the slippage dislocation along grain boundaries, which ultimately brings about embrittlement of the alloy.

Table 5. The hardness of alloys at solution treated and aged conditions.

\begin{tabular}{|c|c|c|c|c|c|}
\hline Hardness (HV) & Standard (Min) & $\begin{array}{c}\text { Base } \\
\text { (718Plus) }\end{array}$ & $\begin{array}{c}\text { Zr- } \\
\text { doped }\end{array}$ & $\begin{array}{c}\text { B- } \\
\text { doped }\end{array}$ & $\begin{array}{c}\text { Zr, B- } \\
\text { doped }\end{array}$ \\
\hline Solution Treated & $270-340$ & 296 & 334 & 320 & 340 \\
\hline Age Hardened & $410-480$ & 430 & 460 & 445 & 473 \\
\hline
\end{tabular}

In the B-doped alloy, the enhanced hardness can be attributed to the presence of borides and boron carbide precipitates in the microstructure. Due to the low impact of boron on segregation of precipitates in grain boundaries as compared to zirconium, this element left weaker impact on the grain boundary embrittlement. In this regard, Xiao et al. [23] reported the positive effect of boron on IN718. This element shifts the failure mode from inter-granular to intra-granular through forming borides and boron carbide precipitates on grain boundaries and increasing their level of cohesion and stability.

According to Table 5, the alloy containing both boron and zirconium has the highest level of hardness. This can be mainly explained by the involvement of a high percentage of $\delta$, carbide and boron carbide precipitates in the alloy's microstructure. Although zirconium simultaneously contributed to both hardness of grains and grain boundaries, the distinct impact of boron was only increase in hardness of grains.

The results of stress-rupture test for the samples are shown in Figure 6. As can be seen, the rupture life of the Zr-doped alloy raised over 2.5 times higher than the base alloy, which can be associated with the increased twins in the microstructure (Figure $2 b$ ) as well as $\delta$ and zirconium carbide precipitates on the grain boundaries. In other words, zirconium created numerous obstacles against mobility of dislocations. On the other hand, the locked up dislocations behind grain boundaries and their slow mobility delay the grain boundaries slippage. The reduction in grain boundaries slippage consequently leads to an increased rupture life of the alloy.

The rupture life of the B-doped alloy similarly demonstrates a 3.5-fold increase as compared to the base alloy. The increased percentage of borides and boron carbide precipitates on grain boundaries and the reduced solidification range of the alloy are the main reasons to the lengthened life. In this regard, Antony and Radavich [9] pointed out the reduced solidification range of a nickel-based superalloy in the presence of boron as explanation to the reduced percentage of fine porosity and improved cohesion of grain boundaries. The researchers also mentioned the effect of boron on increased amount of 
$\mathrm{M}_{3} \mathrm{~B}_{2}$ precipitates and improved cohesion on grain boundaries, which was accompanied by lengthened rupture life of the alloy. Furthermore, the absence of this element in the composition was considered as a factor contributing to higher percentage and lower cohesion of MC carbide precipitates on grain boundaries.

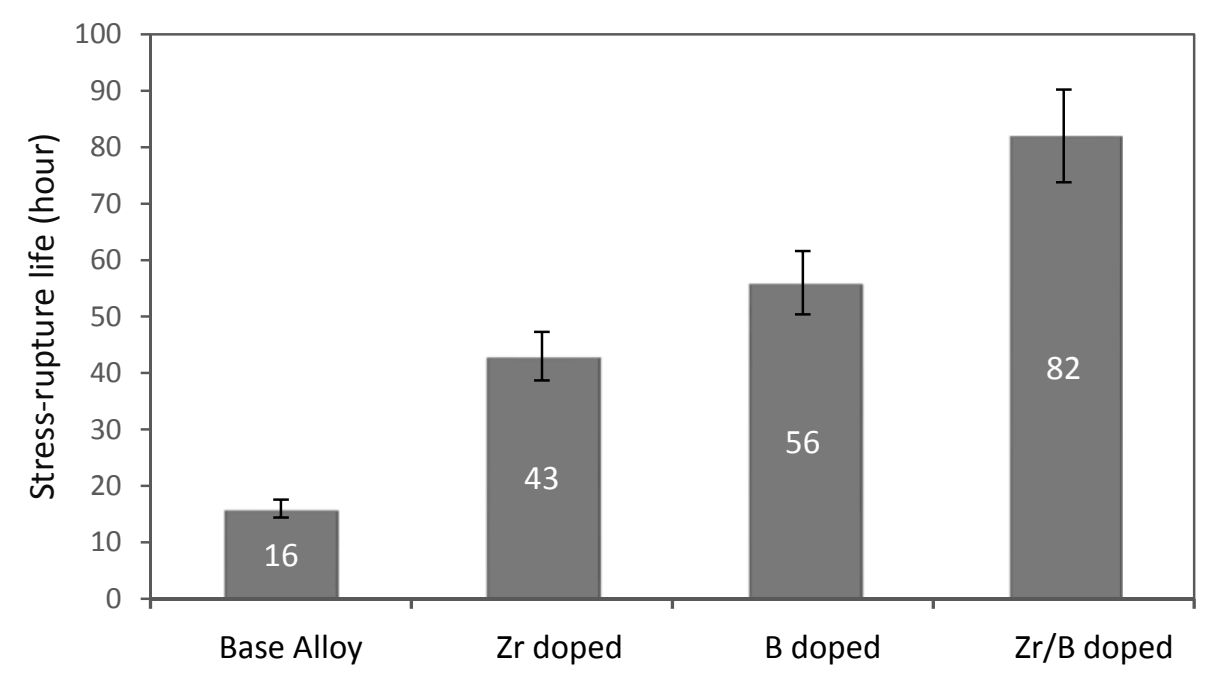

Fig. 6. Effect of boron and zirconium on stress-rupture life of $718 P$ Plus $\left(704^{\circ} \mathrm{C} / 620 \mathrm{MPa}\right)$.

The alloy containing both boron and zirconium demonstrated the highest rupture life as compared to the base alloy. The rupture life was extended by about 5 times higher than the base alloy with zirconium slowing down the dislocations mobility and grain boundary slippage with boron improving the grain boundaries cohesion. In fact, the two elements tend to fill in the cavities around the grain boundaries, thus preventing the growth of $\mathrm{M}_{23} \mathrm{C}_{6}$ carbide precipitates while significantly enhancing grain boundaries cohesion [24]. On the other hand, the segregation of the two elements, i.e., boron and zirconium, on the grain boundaries reduces their energy level [25]. The reduction in energy of grain boundaries ultimately leads to an improved cohesion and subsequently, lengthened stress-rupture life as well as creep life of the alloy.

\section{Conclusions}

1. Both boron and zirconium increase 718Plus hardness through reducing grain size and increasing the percentage of carbide and $\delta$ precipitates.

2. Zirconium leads to 2.5 -fold increase in stress-rupture life of the alloy through increasing the percentage of $\delta$ and $\mathrm{Zr}$-carbide precipitates on grain boundaries and increasing the twins in the microstructure. Moreover, boron enhances the stress-rupture life of the alloy by 3.5 times through increasing the percentage of boron carbide precipitates on grain boundaries and improving their cohesion.

3. The simultaneous presence of boron and zirconium in the 718Plus composition, leads to improved cohesion and strength of grain boundaries and reduces their energy level. This increases the stress-rupture life up to 82 hours. 
4. Increase in the percentage of zirconium together with boron in the alloy's composition extremely enhanced carbide and $\delta$ phases, as well as their excessive agglomeration, in certain spots of the microstructure.

\section{References}

[1] M.C. Kushan, S.C. Uzgur, Y. Uzunonat, F. Diltemiz, Recent advances in aircraft technology. InTech, Rijeka (Croatia) (2012) 75-96.

[2] R.E. Schafrik, D.D. Ward, J.R. Groh, Superalloys 718, 625, 706 and various derivatives (2001) 1-11.

[3] R. Kennedy, Superalloys 718 (2005) 625-706.

[4] W. Cao, R. Kennedy, Superalloys 2004 (2004) 91-99.

[5] X. Xie, C. Xu, G. Wang, J. Dong, W. Cao, R. Kennedy, Metals \& Materials Society (2005) 193-202.

[6] O. Adegoke, Degree Project in Metal Forming and. Surface Technology (2012).

[7] R.F. Decker, J.W. Freeman, NACA TN 4286, (1957).

[8] W. Pennington, Metal Progr. 73 (1958) 82-86.

[9] K. Antony, J. Radavich, Proceedings of The Third International Symposium, Claitor Publishing, (1976) 137-146.

[10] Y. Zhu, S. Zhang, T. Zhang, L. Lou, Y. Tong, X. Ning, Z. Hu, X. Xie, Superalloys $718,625,706$ and various derivatives (1994) 89-98.

[11] N. Li, W. Sun, Y. Xu, S. Guo, D. Lu, Z. Hu, Materials Letters 60 (2006) 2232-35.

[12] D. Heydari, A.S. Fard, A. Bakhshi, J.-M. Drezet, Journal of Materials Processing Technology 214 (2014) 681-87.

[13] L. Yamin, L. Hongjun, L. Jie, W. Zhipeng, H. Yuan, Research \& Development 9 (2012) 6-10.

[14] T. Fedorova, J. Rösler, B. Gehrmann, J. Klöwer, Superalloy 718 and Derivatives (2010) 836-46.

[15] T. Alam, P.J. Felfer, M. Chaturvedi, L.T. Stephenson, M.R. Kilburn, J.M. Cairney, Metallurgical and Materials Transactions A 43 (2012) 2183-91.

[16] Z.-j. MIAO, A.-d. SHAN, Y.-b. WU, J. LU, Y. HU, J.-1. LIU, H.-w. SONG, Transactions of Nonferrous Metals Society of China 22 (2012) 318-23.

[17] J. Andersson, G. Sjöberg, J. Larsson, Superalloy 718 and Derivatives (2010) 43954.

[18] W.-D. Cao, Sixth International Special Emphasis Symposium on Superalloys 718, 625, 706 and Derivatives, 2005, p. 165.

[19] Z. Simona, J. DOBROVSKÁ, B. SMETANA, M. ȚALUDOVÁ, Metal 2011 (2011).

[20] A. Mitchell, A. Schmalz, C. Schvezov, S. Cockroft, Superalloys 718, 625 and various derivatives (1994) 65-78.

[21] H.-E. Huang, C.-H. Koo, Materials Transactions 45 (2004) 554-61.

[22] D. Lin, Y. Gu, J. Guo, MRS Proceedings. Cambridge Univ Press, 1994, p. 885.

[23] L. Xiao, M.C. Chaturvedi, D. Chen, Journal of materials engineering and performance 14 (2005) 528-38.

[24] E. Ross, C.T. Sims, C.T. Sims, N. Stoloff, W. Hagel, Superalloys II. Wiley, New York, 1987.

[25] W. Wang, Reverse engineering: Technology of reinvention, CRC Press, 2010. 